\title{
Media Pembelajaran Zoolfabeth Menggunakan Multimedia Interaktif untuk Perkembangan Kognitif Anak Usia Dini
}

\section{Ni Komang Ayu1 ${ }^{*}$, I. B. Surya Manuaba ${ }^{2}$}

1,2 Jurusan Pendidikan Dasar, Universitas Pendidikan Ganesha, Singaraja, Indonesia

\section{ART I CLE I N F O}

Article history:

Received 27 April 2021

Revised 29 April 2021

Accepted 21 Juli 2021

Available online 25 Agustus 2021

Kata Kunci:

Zoolfabeth, Multimedia Interaktif

Keywords:

Zoolfabeth, Interactive Multimedia

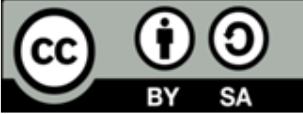

This is an open access article under the CC BY-SA license.

Copyright $(2021$ by Author. Published by Universitas Pendidikan Ganesha.

\begin{abstract}
A B S T R A K
Penelitian ini dilakukan berdasarkan masalah yang ada paa pembelajaran daring di masa pandemi. Guru memerlukan media pembelajaran yang menarik dalam proses pembelajaran daring. Tujuan dari penelitian ini adalah untuk menghasilkan rancang bangun dan mengetahui validitas media pembelajaran zoolfabeth menggunakan multimedia interaktif untuk perkembangan kongnitif anak usia dini. Jenis penelitian ini adalah penelitian pengembangan (research and development) dengan menggunakan model ADDIE. Subjek yang terlibat dalam penelitian ini terdiri dari ahli isi pembelajaran, ahli desain pembelajaran, ahli media pembelajaran, dan anak usia dini dengan kemampuan yang berbeda-beda. Pengumpulan data dalam penelitian dilakukan dengan menggunakan metode non tes dengan intrumen berupa lembar kuesioner. Data yang diperoleh kemudian dianalisis menggunakan teknik analisis deskriptif kuantitatif. Hasil uji validitas oleh ahli isi pembelajaran, ahli desain pembelajaran memperoleh kualifikasi baik, ahli media pembelajaran memperoleh skor 88,45 dengan kualifikasi baik, dan uji coba perorangan memperoleh skor $92,50 \%$ dengan kualifikasi sangat baik. Berdasarkan hasil tersebut dapat disimpulkan bahwa media pembelajaran zoolfabeth menggunakan multimedia interaktif pada perkembangan kongnitif ini layak digunakan untuk anak usia dini. Implikasi dari penelitian ini adalah media zoolfabeth menggunakan multimedia interaktif ini dapat menjadi solusi atas permasalahan pada pembelajaran daring, khususnya untuk membuat pembelajaran menjadi lebih bervariasi.
\end{abstract}

\section{A B S T RACT}

This research was conducted based on the problems that exist in online learning during the pandemic. Teachers need interesting learning media in the online learning process. The purpose of this study was to produce a design and determine the validity of zoolfabeth's learning media using interactive multimedia for early childhood cognitive development. This type of research is research and development using the ADDIE model. The subjects involved in this study consisted of learning content experts, instructional design experts, learning media experts, and early childhood children with different abilities. Data collection in the study was carried out using a non-test method with an instrument in the form of a questionnaire sheet. The data obtained were then analyzed using quantitative descriptive analysis techniques. The results of the validity test by learning content experts, learning design experts obtained good qualifications, learning media experts obtained a score of 88.45 with good qualifications, and individual trials obtained a score of $92.50 \%$ with very good qualifications. Based on these results, it can be concluded that the zoolfabeth learning media using interactive multimedia on cognitive development is appropriate for use in early childhood. The implication of this research is that zoolfabeth media using interactive multimedia can be a solution to problems in online learning, especially to make learning more varied.

\section{PENDAHULUAN}

Anak usia dini merupakan anak yang berada pada rentang usia 0-6 tahun, pada usia ini anak memiliki masa peka dalam perkembangannya dan terjadi pematangan fungsi-fungsi fisik dan psikis yang siap merespon berbagai rangsangan dari lingkungannya (Khairi, 2018; Pebriana, 2017). Pendidikan anak usia dini merupakan upaya pemberian stimulus pendidikan untuk menyiapkan anak pada pendidikan lebih lanjut. Pendidikan anak usia dini dapat diselenggarakan pada jalur formal, non-formal, maupun 
informal. Tujuan dari pendidikan anak usia dini adalah untuk membantu anak dalam mengembangkan potensi-potensi secara intelektual, perkembangan anak berbeda-beda, baik intelegensi, bakat, minat, kreativitas, kematangan emosi, kepribadian, kemandirian jasmani dan sosialnya (Astuti \& Aziz, 2019; Isbayani et al., 2015). Pendidikan anak usia dini merupakan masa penting dalam perkembangan anak, karena pada masa ini adalah kesempatan bagi guru untuk menanamkan hal-hal yang fundamental kepada anak (Nuraeni et al., 2019; Rahelly, 2018). Mengenal huruf sejak dini akan berdampak pada kehidupan sosial anak dan anak dapat bersosialisasi dengan tutur bahasa yang baik (Rosalina \& Nugrahani, 2019).

Pelaksanaan pembelajaran anak usia dini akan lebih bermakna apabila dilaksanakan dengan bantuan media pembelajaran. Media pembelajaran adalah segala sesuatu yang dapat digunakan untuk menyalurkan bahan ajar dari guru ke siswa, sehingga dapat merangsang pikiran, perasaan, perhatian dan minat peserta didik (Syukri, 2020; Zaini \& Dewi, 2017). Penggunaan media pembelajaran akan mampu mengalihkan perhatian anak agar tidak cepat bosan saat belajar, selain itu media juga mampu meningkatkan konsentrasi anak dalam suatu kegiatan dengan waktu yang cukup lama dibandingkan dengan tidak menggunakan media pembelajaran (Abidin, 2016; Mahardika et al., 2019). Hanya saja dalam pelaksanaan pembelajaran daring seperti saat ini penggunaan media pembelajaran dalam kegiatan belajar masih sangat minim. Hal ini dapat diketahui berdasarkan hasil observasi yang telah dilakukan di TK Kumara Dharma Kerti Denpasar. Hasil observasi menunjukkan bahwa pembelajaran di masa pandemi membuat pembelajaran pada anak usia dini menimbulkan banyak permasalahan terutama pada penggunaan media pembelajaran. Pembelajaran yang biasanya dilakukan antara pendidik dengan peserta didik di sekolah dengan bertatap muka langsung, kini hanya dapat dilakukan melalui media komunikasi seperti HP dan laptop. Hal tersebut kemudian berdampak pada sulitnya proses penyampaian materi oleh guru. Jika dibiarkan secara terus menerus, permasalahan yang muncul pada pembelajaran daring akan berpengaruh terhadap hasil belajar serta kemampuan anak usia dini. Adapun upaya yang dapat dilakukan untuk mengatasi hal tersebut yakni dengan mengembangkan sebuah media pembelajaran yang mampu memfasilitasi proses belajar siswa. Salah satu media yang dianggap sesuai yakni media pembelajaran zoolfabeth. Zoolfabeth merupakan media pembelajaran yang dapat digunakan untuk mengenalkan huruf kepada anak melalui gambar-gambar binatang yang dibuat secara menarik. Melalui penggunaan media zoolfabeth anak akan diajak untuk belajar sambil bermain. Kegiatan bermain akan dapat mempengaruhi perkembangan ekspresi bahasa, keterampilan komunikasi, perkembangan emosi, ketrampilan sosial, ketrampilan pengambilan keputusan, dan perkembangan kognitif pada anak-anak (Astuti \& Aziz, 2019). Kegiatan pengenalan huruf menggunakan media zoolfabeth dapat dilakukan dengan berbagai cara yang bervariasi dan dengan strategi yang beragam (Andriyani \& Susilowibowo, 2018; Astuti \& Aziz, 2019).

Salah satu cara yang dapat digunakan yakni dengan menyajikan media zoolfabeth dalam bentuk multimedia interaktif. Multimedia interaktif merupakan kombinasi berbagai media dari komputer, video, audio, gambar dan teks yang dapat menciptakan pembelajaran yang inovatif (Abhyasari et al., 2020; Syafrizal et al., 2018). Penggunaan Multimedia interaktif dapat mempengaruhi pengalaman belajar anak dalam mengenal huruf, penggunaan multimedia interaktif juga dapat mempengaruhi perkembangan kognitif (Fardiah et al., 2019; Syukri, 2020). Apalagi pada era teknologi yang berkembang sangat pesat seperti saat ini, guru bisa membuat media pembelajaran interaktif yang berfariasi untuk mendukung proses pembelajaran daring. Motivasi belajar anak akan meningkat jika pembelajaran dilakukan dengan bervariasi yang membantu anak dalam memahami materi pembelajaran (Permana \& Nourmavita, 2017; Sentarik \& Kusmariyatni, 2020). Media zoolfabeth menggunakan multimedia interaktif ini dirancang dengan memanfaatkan perkembangan teknologi yang ada dan dapat diakses melalui smartphone. Selain itu media zoolfabeth menggunakan multimedia interaktif dapat digunakan dimanapun dan kapanpun, sehingga cocok digunakan untuk pembelajaran daring.

Pemilihan media zoolfabeth berbasis multimedia interaktif yang dikembangkan berupa aplikasi berfungsi untuk memudahkan anak dalam belajar mengenal huruf dan membuat anak tidak bosan dalam belajar daring karena media dikemas dengan semenarik mungkin yang berisi materi, audio, gambargambar animasi dan game. Penggunaan pada media ini juga bisa dilakukan dimana saja dan efisien untuk guru dalam memberikan pembelajaran secara daring. Beberapa penelitian sebelumnya yang berkaitan dengan penggunaan media zoolfabeth dengan multimedia interaktif menunjukkan hasil bahwa multimedia interaktif dapat digunakan untuk mengenalkan huruf, angka dan warna untuk anak usia dini (Tresnawati \& Hidayat, 2017). Penelitian lainnya juga menunjukkan bahwa pengembangan multimedia pembelajaran interaktif menunjukkan hasil yang efektif didalam meningkatkan hasil belajar IPA sehingga layak untuk digunakan dalam proses pembelajaran (Dwiqi et al., 2020). Hasil ini sejalan dengan penelitian ketiga yang juga mengungkapkan bahwa aplikasi multimedia interaktif memiliki validitas yang sangat baik sehingga sangat layak dikembangkan dan dibelajarkan pada materi pembalajaran huruf dan angka untuk usia dini (Mado et al., 2021). Berdasarkan hasil beberapa hasil penelitian terdahulu dapat dikatakan bahwa penggunaan multimedia interaktif sangat efektif digunakan untuk meningakatkan pengetahuan 
serta keterampilan peserta didik kususnya anak usia dini. Hanya saja pada penelitian sebelumnya belum terdapat penelitian yang mengkaji mengenai pengembangan media zoolfabeth menggunakan multimedia interaktif, sehingga penelitian ini difokuskan pada pengembangan media zoolfabeth menggunakan multimedia interaktif dengan tujuan untuk menghasilkan rancang bangun dan mengetahui validitas media pembelajaran zoolfabeth menggunakan multimedia interaktif untuk perkembangan kongnitif anak usia dini.

\section{METODE}

Peneitian ini merupakan jenis penelitian pengembangan (research and development). Produk media pembelajaran zoolfabeth pada penelitian ini dikembangkan dengan menggunakan model ADDIE yang terdiri dari lima tahapan yaitu analisis (analyze), perancangan (design), pengembangan (development), implementasi (implementation), evaluasi (evaluation). Adapun rancangan metode pengembangan ADDIE dapat dilihat pada gambar 1.

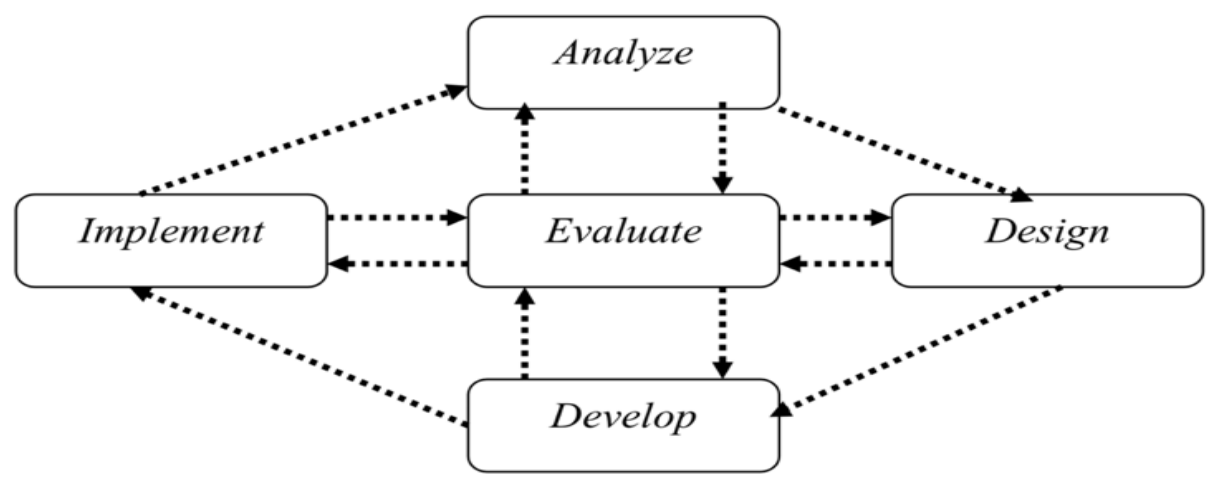

Gambar 1. Tahap Penelitian Model ADDIE (Sumber: Tegeh, dkk., 2014)

Subjek pada penelitian ini berjumlah 5 orang diantaranya adalah 1 orang ahli isi pembelajaran, 1 orang ahli desain pembelajaran dan ahli media pembelajaran, dan untuk uji coba perorangan digunakan 3 orang anak kelompok B TK Kumara Dharma Kerti Denpasar dengan kemampuan tinggi, sedang, dan rendah. Ahli isi pembelajaran, ahli desain pembelajaran, dan ahli media pembelajaran merupakan seorang dosen yang mengajar di Jurusan Pendidikan Dasar di Universitas Pendidikan Ganesha. Pengumpulan data dalam penelitian dilakukan dengan menggunakan metode nontes dengan intrumen berupa lembar kuesioner. Kuesioner diberikan kepada para ahli dan juga anak kelompok B pada uji coba perorangan untuk menentukan dan mengetahui validitas produk. Data diolah dengan menggunakan teknik analisis deskriptif kuantitatif. Adapun kisi-kisi instrumen yang digunakan untuk mengumpulkan data pada uji validitas dan uji coba perorangan dapat dilihat pada tabel 1,2,3 dan 4 . Untuk dapat memberikan makna dan pengambilan keputusan digunakan ketetapan konversi skala 5 yang disajikan pada tabel 5.

Tabel 1. Kisi - Kisi Instrumen Ahli Isi Pembelajaran

\begin{tabular}{|c|c|c|c|}
\hline Aspek & Indikator & No. Butir & Jumlah Butir \\
\hline \multirow{2}{*}{ Kurikulum } & 1. Tujuan pembelajaran & 1 & \multirow{2}{*}{2} \\
\hline & 2. Kesesuain kompetensi dasar dan indikator & 2 & \\
\hline \multirow{6}{*}{ Materi } & 1. Ketepatan materi & 3 & \multirow{7}{*}{6} \\
\hline & 2. Kemenarikan materi & 4 & \\
\hline & 3. Materi mudah dipahami & 5 & \\
\hline & 4. Kebenaran materi & 6 & \\
\hline & 5. Kesesuain materi dengan karakteristik anak & 7 & \\
\hline & 6. Materi didukung media yang tepat & 8 & \\
\hline \multirow{3}{*}{ Kebahasaan } & 1. Pengunaan bahasa yang tepat dan konsisten & 9 & \\
\hline & 2. Bahasa yang digunakn sesuai dengan karakteristik anak & 10 & \multirow[t]{2}{*}{3} \\
\hline & 3. Bahasa yang digunakan mudah dipahami & 11 & \\
\hline Evaluasi & 1. Kejelasan target hasil belajar & 12 & 1 \\
\hline \multicolumn{3}{|c|}{ Jumlah } & 12 \\
\hline
\end{tabular}

(Sumber: Suartama, 2016 dengan modifikasi peneliti) 
Tabel 2. Kisi - Kisi Instrumen Desain Pembelajaran

\begin{tabular}{|c|c|c|c|}
\hline Aspek & Indikator & $\begin{array}{c}\text { No. } \\
\text { Butir }\end{array}$ & $\begin{array}{c}\text { Jumlah } \\
\text { Butir }\end{array}$ \\
\hline \multirow[t]{3}{*}{ Tujuan } & 1. Kejelasan tujuan pembelajaran & 1 & 1 \\
\hline & 1. Kegiatan pembelajaran dapat memotivasi anak & 2 & \multirow{5}{*}{5} \\
\hline & 2. Penyampaian materi memberikan langkah-langkah yang logis & 3 & \\
\hline \multirow[t]{3}{*}{ Strategi } & $\begin{array}{l}\text { 3. Memberikan materi dalam media dapat membantu anak mengingat } \\
\text { pengetahuan yang pernah diberikan }\end{array}$ & 4 & \\
\hline & 4. Langkah-langkah pengunaan media sudah jelas & 5 & \\
\hline & 5. Penyampaian materi menarik & 6 & \\
\hline Evaluas & 1. Pegunaan materi pada media & 7 & \multirow{2}{*}{2} \\
\hline $\mathrm{i}$ & 2. Diberikan evaluasi untuk mengukur kemampuan anak & 8 & \\
\hline \multicolumn{3}{|c|}{ Jumlah } & 8 \\
\hline
\end{tabular}

Tabel 3. Kisi - Kisi Instrumen Media Pembelajaran

\begin{tabular}{|c|c|c|c|}
\hline Aspek & Indikator & No. Butir & Jumlah Butir \\
\hline \multirow{5}{*}{ Desain Pesan } & 1. Media mudah digunakan & 1 & \multirow{5}{*}{5} \\
\hline & $\begin{array}{l}\text { 2. Bentuk dan warna pada masing-masing } \\
\text { tombol dalam media sudah sesuai }\end{array}$ & 2 & \\
\hline & $\begin{array}{l}\text { 3. Komposisi dan kombinasi warna dan } \\
\text { musik yang tepat dan serasi }\end{array}$ & 3 & \\
\hline & 4. Desain tampilan & 4 & \\
\hline & 5. Keterbacaan teks & 5 & \\
\hline \multirow{3}{*}{$\begin{array}{c}\text { Pengoperasian } \\
\text { Ketepatan dan Teknik } \\
\text { Kejelasan }\end{array}$} & 1. Kemudahan penggunaan media & 6 & 1 \\
\hline & $\begin{array}{l}\text { 1. Gambar dalam media sudah terlihat jelas } \\
\text { dan sesuai }\end{array}$ & 7 & \multirow[b]{2}{*}{2} \\
\hline & $\begin{array}{l}\text { 2. Ukuran huruf yang digunakan sudah jelas } \\
\text { dan mudah dibaca }\end{array}$ & 8 & \\
\hline & Jumlah & & 8 \\
\hline
\end{tabular}

(Sumber: Suartama, 2016 dengan modifikasi peneliti)

Tabel 4. Kisi - Kisi Instrumen Uji Coba Perorangan

\begin{tabular}{|c|c|c|c|}
\hline Aspek & Indikator & No. Butir & Jumlah Soal \\
\hline \multirow{4}{*}{ Desain Pesan } & 1. Kejelesan gambar & 1 & \multirow{4}{*}{, } \\
\hline & 2. Kejelasan suara & 2 & \\
\hline & 3. Kemenarikan desan produk & 3 & \\
\hline & 4. Keterbacaan teks & 4 & \\
\hline \multirow{2}{*}{ Materi } & 1. Kemudahan pemahaman materi & 5 & \multirow{2}{*}{2} \\
\hline & 2. Kejelasan uraian materi & 6 & \\
\hline Pengoperasian & 1. Kemudahan pengoperasian & 7 & 1 \\
\hline Motivasi & 1. Media memberikan Semangat & 8 & 1 \\
\hline
\end{tabular}

(Sumber: Suartama, 2016 dengan modifikasi peneliti)

Tabel 5. Konversi Tingkat Pencapaian dengan Skala 5

\begin{tabular}{ccc}
\hline Tingkat Pencapaian (\%) & Kualifikasi & Keterangan \\
\hline $90-100$ & Sangat Baik & Tidak Perlu Direvisi \\
$75-89$ & Baik & Sedikit Revisi \\
$65-79$ & Cukup & Direvisi Secukupnya \\
$55-64$ & Kurang & Banyak Hal Yang Direvisi \\
$1-54$ & Sangat Kurang & Diulang Membuat Produk \\
\hline
\end{tabular}




\section{HASIL DAN PEMBAHASAN}

Hasil

Pada bagian ini secara umum akan membahas dua hal yaitu rancang bangun dan validitas media zoolfabeth. Rancang bangun pada penelitian ini dikembangkan menggunakan model pengembangan ADDIE yang terdiri dari lima tahapan yaitu analisis (analyze), perancangan (design), pengembangan (development), implementasi (implementation), evaluasi (evaluation). Validitas dilakukan untuk mengetahui kelayakan media zoolfabeth yang dilakukan oleh ahli isi pembelajaran, ahli desain pembelajaran, ahli media pembelajaran, dan anak kelompok B TK Kumara Dharma Kerti Denpasar pada uji coba perorangan. Tahap pengembangan pertama yakni tahap analisis. Tahap analisis dilakukan dengan mengidentifikasi kebutuhan-kebutuhan dalam penelitian pengembangan zoolfabeth. Analisis mengenai kebutuhan guru dan anak dilakukan melalui kegiatan wawancara yang dilakukan ditempat penelitian. Wawancara ini dilakukan untuk mengetahui apa saja kebutuhan guru dan anak dalam pembelajaran dan mencari solusi yang tepat dalam meningkatkan kualitas pembelajaran. Dari hasil wawancara yang telah dilakukan dengan guru kelompok B1 diketahui bahwa dalam melaksanakan pembelajaran guru merasa kesulitan dalam menjelaskan materi pada anak, hal ini dikarenakan guru hanya menggunakan media cetak untuk menjelaskan materi dan penugasan sehingga tingkat pemahaman materi anak masih kurang dan anak menjadi lebih cepat bosan.

Tahap pengembangan kedua yakni tahap desain. Pada tahap desain dilakukan proses mendesain atau merancang sebuah pembelajaran dengan media zoolfabeth melalui multimedia interaktif untuk perkembangan kognitif anak. Tahap merancang atau mendesain konsep produk dengan kerangka acuan yaitu pemilihan materi sesuai dengan karakteristik peserta didik dan tuntutan kompetensi, strategi pembelajaran, bentuk dan metode asesmen dan evaluasi. Disamping itu peneliti juga membuat storyboard dan flowchart yang digunakan sebagai pedoman dalam mengembangkan produk. Tahap ketiga yakni tahap pengembangan. Tahap pengembangan adalah proses mewujudkan desain menjadi kenyataan, yaitu proses pengembangan media zoolfabeth melalui multimedia interaktif berdasarkan kriteria-kriteria yang telah ditentukan. Kegiatan pengembangan produk juga dilakukan berdasarkan rancangan yang telah dibuat pada tahap sebelumnya dan juga merujuk pada storyboard dan flowchart. Pengembangan meliputi pemilihan dan menyeleksi unsur-unsur yang ada dalam media seperti gambar, warna, suara, teks dan halhal lain terkait bentuk visual video.

Tahap keempat yakni tahap implementasi. Tahap implementasi adalah langkah nyata untuk menerapkan media zoolfabeth melalui multimedia interaktif kepada anak kelompok B untuk pengenalan huruf, media yang dibuat bertujuan untuk mengetahui keefeftivitas, menarik serta efisien saat digunakan. Pada tahap implementasi ini peneliti menguji validitas produk untuk mengetahui kelayakan produk. Tahap pengembangan yang terakhir yakni tahap evalusia yang dilakukan dengan melaksanakan evaluasi formatif dan evaluasi sumatif. Evaluasi formatif dilakukan untuk mengukur atau menilai produk yang dikembangkan yang mencangkup validitas ahli dan uji coba perorangan. Sedangkan evaluasi sumatif dilakukan untuk mengetahui efektif atau tidak produk yang dikembangkan. Adapun hasil pengembangan media zoolfabeth yaitu sebagai berikut. Validitas pengembangan media media zoolfabeth menurut uji ahli ahli isi pembelajaran, ahli desain pembelajaran, ahli media pembelajaran dan hasil uji coba produk pada anak, secara ringkas disajikan pada tabel 6 sebagai berikut.

Tabel 6. Persentase Hasil Validitas Media Media Zoolfabeth

\begin{tabular}{crcc}
\hline No & Subjek Uji Coba & Hasil Validitas (\%) & Kualifikasi Persentase \\
\hline 1. & Uji Ahli Isi Pembelajaran & 90,38 & Sangat Baik \\
2. & Uji Ahli Desain Pembelajaran & 86,11 & Baik \\
3. & Uji Ahli Media Pembelajaran & 88,88 & Baik \\
4. & Uji Coba Perorangan & 92,50 & Sangat Baik \\
\hline
\end{tabular}

\section{Pembahasan}

Penelitian ini dikembangkan media pembelajaran zoolfabeth untuk perkembangan kognitif pada anak usia dini. Pengembangkan media ini mengacu pada pengenalan huruf untuk memudahkan anak untuk menghafal huruf sejak dini, namun kenyataannya didalam pembelajaran yang berlangsung dengan sistem daring ini minim adanya interaksi antara guru dengan anak dan kurang penggunaan media pembelajaran yang inovatif sehingga pembelajaran cenderung monoton dan membosankan bagi anak, sehingga memuculkan inovasi baru untuk mengembangkan sebuah media pembelajaran berbasis multimedia intraktif yang lengkapa berisi materi, audio, gambar-gambar animasi dan games yang dikemas menarik dan dapat membantu guru dalam proses pembelajaran daring. Berdasarkan analisis hasil penelitian didaptkan 4 temuan dalam penelitian ini, diantaranya adalah. 
Temuan pertama berkaitan dengan hasil uji validitas oleh ahli isi pembelajaran yang memperoleh kualifikasi sangat baik. Isi media zoolfabeth ini memiliki materi yang mudah dipahami dengan bantuan visual yang menarik. Sebuah media harus dirancang sesuai dengan kebutuhan anak dan situasi pembelajaran agar media bisa digunakan secara maksimal (Fithri \& Setiawan, 2017; Sari \& Setiawan, 2020). Media pembelajaran memiliki peran penting dalam proses penyampaian informasi kepada anak. Media perlu dipersiapkan sebaik mungkin agar tujuan pembelajaran tercapai. Selain itu kubutuhan anak dan situasi dalam proses pembelajaran perlu mendapatkan perhatian dan tentunya harus disesuaikan. Pengenalan huruf kepada anak bisa dilakukan dengan media yang bervariasi yaitu dengan bantuan berbagai ilustrasi yang menarik. Seperti pada media zoolfabet, pengenalan huruf pada anak usia dini disajikan dengan ilustrasi gambar binatang yang divusualiasikan dalam bentuk digital. Hal tersebut akan menarik minat belajar anak.

Temuan kedua berkaitan dengan hasil uji validitas oleh ahli desain pembelajaran memperoleh kualifikasi baik. Media zoolfabeth ini dirancang dengan acuan kondisi dan situasi yang ada. Media zoolfabeth ini dirancang untuk mengenalkan huruf kepada anak dengan berbantuan ilustrasi gambar binatang sebagai petunjuknya. Sebagai tenaga professional guru harus memilih strategi pembelajaran yang tepat agar stimulus yang diberikan kepada siswa bisa dimaksimalkan (Hasana \& Maharany, 2017; Pura \& Asnawati, 2019). Pelaksanaan proses pembelajaran harus perlu diperhatikan dan dipersiapkan dengan baik agar tujuan pembelajaran dapat tercapai (Abidin, 2016; Santoso, 2019). Pelaksanaan pengaplikasian media zoolfabeth ini dilaksankan berdasarkan RPP yang telah dibuat, sehingga dapat berjalan sesuai dengan rancangan yang telah dibuat. RPP merupakan pedoman yang digunakan guru untuk melaksanakan proses pembelajaran agar sesuai dengan yang diinginkan dan tentunya agar dapat mencapai tujuan pembelajaran.

Temuan ketiga berkaitan dengan hasil uji validitas oleh ahli media pembelajaran memperoleh kualifikasi baik. Media zoolfabeth ini pada penelitian ini memiliki visualisasi yang menarik karena terdapat unsur audio visual yang bervariasi. Media pembelajaran berguna untuk memberikan stimulus dan juga sebagai sarana menyampaikan informasi dari guru ke anak (Rozi \& Khomsatun, 2019; Arnada \& Putra, 2018). Media pembelajaran memiliki peran yang sangat penting dalam upaya mencapai tujuan pembelajaran. Perkembangan teknologi seperti saat ini sangat memudahkan guru dalam membuat media pembelajaran yang lebih fleksibel dan tentunya dapat membantu guru dalam menyampaikan materi pembelajaran. Guru di era perkembangan teknologi seperti saat ini harus membekali diri untuk bisa memanfaatkan teknologi agar memberi manfaat penuh kepada proses pembelajaran. Media zoolfabeth ini salah satu pemanfaatan perkembangan teknologi yang membantu guru dalam proses pembelajaran daring.

Temuan keempat berkaitan dengan hasil uji validitas pada uji coba perorangan memperoleh kualifikasi sangat baik. Media zoolfabeth ini memiliki daya tarik bagi anak karena dapat dioperasikan di hand phone dengan tampilan yang bervariasi. Media zoolfabeth termasuk multimedia karena terdapat unsur gambar, video, dan warna, audio yang menarik serta pengaplikasiannya mengajak siswa untuk bermain. Pembelajaran pada anak usia dini memang harus menerapkan konsep belajar sambil bermain, karena anak usia dini dapat menerima pembelajaran dengan cara bermain (Putra \& Hasiana, 2020; Wahyuni et al., 2020). Anak usia dini perlu mendapat perhatian khusus, karena pada masa ini anak berada masa perkembagan yang sangat baik dan sangat pesat (Khoiriyati \& Saripah, 2018; Saripudin, 2019). Anak usia dini pada dasarnya memang sangat menyukai kegiatan bermain. Untuk memberikan pembelajaran kepada mereka harus dipadukan dengan permainan. Dengan kegiatan permainan, proses pembelajaran akan dapat diikuti oleh anak dengan antusias dan tentunya tujuan pembelajaran bisa tercapai.

Hasil yang diperoleh dalam penelitian ini sejalan dengan hasil penelitian terdahulu yang juga mengungkapkan bahwa multimedia interaktif dapat digunakan untuk mengenalkan huruf, angka dan warna untuk anak usia dini (Tresnawati \& Hidayat, 2017). Penelitian lainnya juga menunjukkan bahwa pengembangan multimedia pembelajaran interaktif menunjukkan hasil yang efektif didalam meningkatkan hasil belajar IPA sehingga layak untuk digunakan dalam proses pembelajaran (Dwiqi et al., 2020). Hasil ini sejalan dengan penelitian ketiga yang juga mengungkapkan bahwa aplikasi multimedia interaktif memiliki validitas yang sangat baik sehingga sangat layak dikembangkan dan dibelajarkan pada materi pembalajaran huruf dan angka untuk usia dini (Mado et al., 2021).

Berdasarkan analisis hasil penelitian yang didukung oleh penelitian terdahulu dapat dikatakan bahwa media zoolfabeth dengan menggunakan multimedia interaktif memiliki nilai validitas sangat baik sehingga layak untuk dikembangkan dan dibelajarkan kepada anak usia dini. Implikasi dari penelitian ini adalah media zoolfabeth ini dapat menjadi media pembelajaran yang sangat berguna dalam pembelajaran daring. 


\section{SIMPULAN}

Hasil uji validitas ahli isi pembelajaran mendapatkan kualifikasi baik, ahli desain pembelajaran mendapatkan kualifikasi baik, ahli media pembelajaran mendapatkan kualifikasi baik, dan uji coba perorangan mendapatkan kualifikasi sangat baik. Berdasarkan hasil tersebut dinyatakan bahwa media pembelajaran zoolfabeth menggunakan multimedia interaktif pada perkembangan kongnitif ini layak digunakan dan dikembangkan untuk anak usia dini.

\section{DAFTAR RUJUKAN}

Abhyasari, N. P., Kusmariyatni, N. N., \& Agustiana, I. G. A. T. (2020). Pengaruh Pembelajaran Berpendekatan Saintifik Berbasis Masalah Terhadap Disiplin dan Hasil Belajar IPA. Mimbar PGSD Undiksha, 8(1), 111-122. https://doi.org/http://dx.doi.org/10.23887/jjpgsd.v8i1.24547.

Abidin, Z. (2016). Penerapan Pemilihan Media Pembelajaran. Edcomtech, 1(1), 9-20. http://journal2.um.ac.id/index.php/edcomtech/article/view/1784.

Andriyani, E. W., \& Susilowibowo, J. (2018). Pengembangan LKPD Berbentuk Pop Up Book Sebagai Bahan Ajar Pendukung Pada Materi Utang Kelas XI Akuntansi Di SMK Negeri 4 Surabaya. Jurnal $\begin{array}{lll}\text { Pendidikan Akuntansi (JPAK), } & \text { 6(2). }\end{array}$ https://ejournal.unesa.ac.id/index.php/jpak/article/view/25654.

Arnada, E. Z., \& Putra, R. W. (2018). Implementasi Multimedia Interaktif Pada Paud Nurul Hikmah Sebagai Media Pembelajaran. Jurnal Idealis, 1(5), 393-400. https://jom.fti.budiluhur.ac.id/index.php/ IDEALIS/article/view/1033.

Astuti, R., \& Aziz, T. (2019). Integrasi Pengembangan Kreativitas Anak Usia Dini di TK Kanisius Sorowajan Yogyakarta. Jurnal Obsesi: Jurnal Pendidikan Anak Usia Dini, 3(2), 294. https://doi.org/10.31004/obsesi.v3i2.99.

Dwiqi, G. C. S., Sudatha, I. G. W., \& Sukmana, A. I. W. I. Y. (2020). Pengembangan Multimedia Pembelajaran Interaktif Mata Pelajaran IPA Untuk Siswa SD Kelas V. Jurnal Edutech Undiksha, 8(2), 33. https://doi.org/10.23887/jeu.v8i2.28934.

Fardiah, Murwani, S., \& Dhieni, N. (2019). Meningkatkan Kemampuan Kognitif Anak Usia Dini melalui Pembelajaran Sains. Jurnal Obsesi: Jurnal Pendidikan Anak Usia Dini, 4(1), 133. https://doi.org/10.31004/obsesi.v4i1.254.

Fithri, D. L., \& Setiawan, D. A. (2017). Analisa Dan Perancangan Game Edukasi Sebagai Motivasi Belajar Untuk Anak Usia Dini. Simetris: Jurnal Teknik Mesin, Elektro Dan Ilmu Komputer, 8(1), 225-230. https://doi.org/10.24176/simet.v8i1.959.

Hasana, S. N., \& Maharany, E. R. (2017). Pengembangan Multimedia Menggunakan Visual Basic For Application (Vba) Untuk Meningkatkan Profesionalisme Guru Matematika. JPM : Jurnal Pendidikan Matematika, 3(2), 30. https://doi.org/10.33474/jpm.v3i2.648.

Isbayani, N. S., Sulastri, N. M., \& Tirtayani, L. A. (2015). Penerapan Metode Outbound Untuk Meningkatkan Keterampilan Sosial Emosional Anak. Jurnal Pendidikan Anak Usia Dini Universitas Pendidikan Ganesha, 41(5), 430-443. https://doi.org/http://dx.doi.org/10.23887/paud.v3i1.6148.

Khairi, H. (2018). Karakteristik Perkembangan Anak Usia Dini dari 0-6 Tahun. Jurnal Warna, 2(2), 15-28. https://ejournal.iaiig.ac.id/index.php/warna/article/view/87/91.

Khoiriyati, S., \& Saripah. (2018). Pengaruh Media Sosial pada Perkembangan Kecerdasan Kognitif Anak Usia Dini. Aulada: Jurnal Pendidikan Dan Perkembangan Anak, 1(1), 49-60. https://doi.org/10.31538/aulada.v1i1.209.

Mado, T. W., Mado, Y. J., \& Gusti. (2021). Aplikasi Multimedia Pembalajaran Huruf Dan Angka Untuk Anak Anak. Jurnal In Create (Inovasi Dan Kreasi Dalam Teknologi Informasi), 7(1). http://increate.nusanipa.ac.id/index.php/increate/article/view/20/17.

Mahardika, G. Y., Sindu, I. G. P., \& Suyasa, P. W. A. (2019). Pengembangan Video Pembelajaran Tri Hita Karana Dan Catur Guru Dalam Mata Pelajaran Agama Hindu Untuk Siswa Kelas V Sekolah Dasar "Studi Kasus SDN 1 Tangguwisia." Kumpulan Artikel Mahasiswa Pendidikan Teknik Informatika (KARMAPATI), 8(3), 500-509. https://ejournal.undiksha.ac.id/index.php/janapati/article/ viewFile/9922/6298.

Nuraeni, L., Andrisyah, A., \& Nurunnisa, R. (2019). Efektivitas Program Sekolah Ramah Anak dalam Meningkatkan Karakter Anak Usia Dini. Jurnal Obsesi : Jurnal Pendidikan Anak Usia Dini, 4(1), 20. https://doi.org/10.31004/obsesi.v4i1.204.

Pebriana, P. H. (2017). Analisis Penggunaan Gadget terhadap Kemampuan Interaksi Sosial pada Anak Usia Dini. Jurnal Obsesi: Jurnal Pendidikan Anak Usia Dini, 1(1), 1. https://doi.org/10.31004/obsesi.v1i1.26. 
Permana, E. P., \& Nourmavita, D. (2017). Pengembangan Multimedia Interaktif Pada Mata Pelajaran IPA Materi Mendeskripsikan Daur Hidup Hewan Di Lingkungan Sekitar Siswa Kelas IV Sekolah Dasar. Jurnal PGSD, 10(2), 79-85. https://doi.org/10.33369/pgsd.10.2.79-85.

Pura, D. N., \& Asnawati, A. (2019). Perkembangan Motorik Halus Anak Usia Dini Melalui Kolase Media Serutan Pensil. Jurnal Ilmiah Potensia, 4(2), 131-140. https://doi.org/10.33369/jip.4.2.131-140.

Putra, P. A., \& Hasiana, I. (2020). Mengembangkan Kemampuan Membaca Anak Usia Dini Dengan Multimedia Interaktif. Incrementapedia: Jurnal Pendidikan Anak Usia Dini, 2(02), 19-24. https://doi.org/10.36456/incrementapedia.vol2.no02.a3016.

Rahelly, Y. (2018). Implementasi Kurikulum 2013 Pendidikan Anak Usia Dini (Paud) Di Sumatera Selatan. JPUD - Jurnal Pendidikan Usia Dini, 12(2), 381-390. https://doi.org/10.21009/jpud.122.21.

Rosalina, C. D., \& Nugrahani, R. (2019). Pengembangan Media Buku Pop-up Untuk Pembelajaran Mengenal Huruf Alphabet Anak Usia Dini. Seling:Jurnal Program Studi PGRA, 5(1), 54-63. https://doi.org/https://doi.org/10.29062/seling.v5i1.362.

Rozi, F., \& Khomsatun, K. (2019). Rancang Bangun Game Edukasi Pengenalan Warna Untuk Pendidikan Anak Usia Dini Menggunakan Adobe Flash Berbasis Android. JIPI (Jurnal Ilmiah Penelitian Dan Pembelajaran Informatika), 4(1), 12. https://doi.org/10.29100/jipi.v4i1.781.

Santoso, P. (2019). Pengembangan Media Interaktif Menggunakan Model Assure Untuk Membantu Guru Dalam Pembelajaran Fisika Tentang Alat Ukur Listrik. Briliant: Jurnal Riset Dan Konseptual, 4(2), 235. https://doi.org/10.28926/briliant.v4i2.319.

Sari, K. M., \& Setiawan, H. (2020). Kompetensi Pedagogik Guru dalam Melaksanakan Penilaian Pembelajaran Anak Usia Dini. Jurnal Obsesi: Jurnal Pendidikan Anak Usia Dini, 4(2), 900. https://doi.org/10.31004/obsesi.v4i2.478.

Saripudin, A. (2019). Analisis Tumbuh Kembang Anak Ditinjau Dari Aspek Perkembangan Motorik Kasar Anak Usia Dini. Equalita: Jurnal Pusat Studi Gender Dan Anak, 1(1), 114. https://doi.org/10.24235/equalita.v1i1.5161.

Sentarik, K., \& Kusmariyatni, N. (2020). Media Pop-Up Book pada Topik Sistem Tata Surya Kelas VI Sekolah Dasar. Jurnal Ilmiah Sekolah Dasar, 4(2), 197. https://doi.org/10.23887/jisd.v4i2.25135.

Suartama, I. K. (2016). Evaluasi dan Kriteria Kualitas Multimedia Pembelajaran. Universitas Pendidikan Ganesha.

Syafrizal, A., Andika, R., \& Panggabean, A. P. (2018). Perancangan Game Pembelajaran Anak Usia Dini Menggunakan HTML 5 Berbasis Multimedia Interaktif. Seminar Nasional Teknologi Informasi Dan Multimedia, 7-12. https://ojs.amikom.ac.id/index.php/semnasteknomedia/article/view/2077.

Syukri. (2020). Meningkatkan Kemampuan Kognitif Anak Melalui Media Kartu Angka Bergambar Di Tk Bunaya. Jurnal AL-Abyadh, 3(1), 27=38. https://ojs.diniyah.ac.id/index.php/AlAbyadh/article/view/168.

Tegeh, I. M. (2014). Model Penelitian Pengembangan. Graha Ilmu.

Tresnawati, D., \& Hidayat, E. (2017). Pengembangan Aplikasi Pengenalan Huruf, Angka Dan Warna Untuk Anak Berbasis Multimedia. Jurnal Algoritma, 14(2), 400-409. https://doi.org/10.33364 /algoritma/v.14-2.400.

Wahyuni, I. W., Muazimah, A., \& Misda. (2020). Pengembangan Motorik Kasar Anak Melalui Permainan Tradisional Tarik Upih Berbasis Kearifan Lokal. Jurnal Pendidikan Anak Usia Dini Undiksha, 8(1), 61-68. https://doi.org/http://dx.doi.org/10.23887/paud.v8i1.24307.

Zaini, H., \& Dewi, K. (2017). Pentingnya Media Pembelajaran Untuk Anak Usia Dini. Raudhatul Athfal: Jurnal Pendidikan Islam Anak Usia Dini, 1(1), 81-96. https://doi.org/10.19109/ra.v1i1.1489. 